\title{
Impact of media violence on aggressive attitude for adolescents
}

\author{
Qian Zhang ${ }^{1,2,3 \#}$, Dingyong Xiong ${ }^{4}$, Jingjin Tian ${ }^{1}$ \\ ${ }^{1}$ School of Applied Technology, Southwest University, Chongqing, China; ${ }^{*}$ Corresponding Author: zhq@swu.edu.cn \\ ${ }^{2}$ Faculty of Psychology, Southwest University, Chongqing, China \\ ${ }^{3}$ Center for the Study of Mental Health Education, Southwest University, Chongqing, China \\ ${ }^{4}$ Sichuan Vocational College of Industrial Management, Mianzhu, China; 452547287@qq.com
}

Received 27 October 2013; revised 28 November 2013; accepted 12 December 2013

Copyright (C) 2013 Qian Zhang et al. This is an open access article distributed under the Creative Commons Attribution License, which permits unrestricted use, distribution, and reproduction in any medium, provided the original work is properly cited.

\begin{abstract}
The goal of this study was mainly to examine the impact of media violence on aggressive attitude among Chinese adolescents by using a modified STROOP task. 74 adolescents participated in this study, 37 were assigned to violent movie group and 37 were assigned to non-violent movie group. The results showed significant Movie Type and Trait Aggressiveness interaction, and adolescents with high aggressiveness (HA) had a significantly higher aggressive attitude than adolescents with mild aggressiveness (MA) and low aggressiveness (LA) after watching violent movies. Furthermore, the relation between significant Movie Type and Gender interaction was also found, and boys showed a significantly higher aggressive attitude than girls after watching violent movies. This implied that violent movies could effectively affect aggressive attitude for adolescents in China.
\end{abstract}

Keywords: Media Violence; Aggressive Attitude; Chinese Adolescents; Modified STROOP Task

\section{INTRODUCTION}

A great amount of research demonstrated a stronger effect of violent media (e.g. TV, movie, video games) than non-violent media on aggressive behavior among adolescents [1-3]. Moreover, it was reported that exposure to violent media escalated aggressive cognition, aggressive affect, physiological arousal, aggressive behavior, and decreased prosocial behavior [4,5]. Besides, reward and punishment in violent video games had posi-

*The first two authors (Dingyong Xiong and Qian Zhang) contributed equally to this article, so they were both the first authors. tive impacts on aggressive effect, cognition, and behavior [6]. Beyond that, it was found gender differences existed in aggression after exposing media violence, and that boys were more sensitive to aggression (e.g., hostile feelings, aggressive thoughts, and physiological arousal) compared to girls [7-12]. Specifically, it was indicated that subjects watching violent movies thought more aggressive words by using lexical decision and word association paradigm [13]. Other scholars, however, claimed no pronouncing evidence to conclude that movie violence certainly caused aggressive feelings [14-16]. Based on these arguments mentioned above, it seemed that different arguments still existed on the relationship between violent movie exposure and aggression, which needed researchers to explore in the future.

With the rapid development of film industry, a variety of violent movies (including Hollywood blockbusters) flowed into Chinese movie markets. Under this background, numerous adolescents got easy access to violent movies in their daily life. Thus, they were prone to forming aggressive cognition, attitude and forming violent behavior on account of their strong brain plasticity from a developmental perspective. In reality, adolescents tended to announce that they could solve problems alone by resorting to violence especially when they were frustrated. For example, adolescents with high trait aggressiveness might attack others due to their activated aggressive schema in their brain regardless of behavioral outcomes. As a result, aggressive attitude affected by violent movies may finally result in antisocial behavior, and even led them to commit crimes. Nevertheless, aggression of Chinese adolescents provoked by media violence has not attracted attention from educators, researchers and public policy makers at the moment. Therefore, it was indispensable to investigate in this area, so as to effectively regulate aggressive attitude and to erase hostile feeling, and scientifically control aggressive 
behavior for Chinese adolescents as well.

The present study was to examine the impact of media violence on aggressive attitude for Chinese adolescents. Two types of movie clips were selected as media violence and media non-violence, respectively. Two hypotheses were proposed: 1) HA adolescents may show a significantly stronger aggressive attitude than MA and LA adolescents after viewing violent movies; 2) Boys may show a significantly stronger aggressive attitude than girls after viewing violent movies.

\section{METHOD}

\subsection{Participants}

74 participants (boys $=37$, girls $=37$ ) recruited from a high school in southwestern part of China participated in the study. Participants ranged in age from 15 to 19 years $(\mathrm{M}=16.55, \mathrm{SD}=1.27)$, with normal vision correction and no color blindness. 37 participants watching STREET FIGHTER were regarded as violent movie group, and 37 participants watching AIR CRISIS were deemed as nonviolent movie group.

\subsection{Materials}

\subsubsection{Movie Clips}

2 types of movie clips were selected, including STREET FIGHTER (violent movie clip) and AIR CRISIS (non-violent movie clip), were selected as media violence and media non-violence. STREET FIGHTER told a former special military officer who sneaked into the most dangerous underground fight clubs to look for avenge the enemy for his brother. His brother was forced to participate in the fighting game because of a gambling debt, so that he was now in a coma situation. Fragment selected was a wrestling scene. AIR CRISIS told a flight travels from Berlin to New York, and the heroine endured the grief of unexpected death of her husband. She was eager to get back home with a young daughter as soon as possible. The lovely 6-year-old daughter was lost after the airplane shortly took off and the firmly mother began to look for her daughter on the plane. The fragment selected told the looking process. The time of each movie clip lasted for roughly 15 minutes. The violent movie clip consisted of body-fighting scenes between two males with language attack, whereas the non-violent movie clip included no body-fighting contents and language attacks.

\subsubsection{Goal Words}

50 aggressive and 50 nonaggressive words were randomly matched to be presented on the computer screen. These words were presented in three colors (green, red, blue) in NO. 48 black with a gray background. The presented order of goal words was counterbalanced.

\subsubsection{Measures}

Buss-Perry Aggression Questionnaire (BPAQ) [17], a 5-point rating scale, was used to measure trait aggressiveness (HA, MA, LA) of all participants in this study.

\subsection{Experimental Design}

Multi-factor experimental design was used, with movie type, gender and trait aggressiveness as independent variables and aggression as dependent variable. 2 (movie type: violent vs. non-violent) $\times 2$ (goal word: aggressive vs. nonaggressive) $\times 3$ (trait aggressiveness: HA, MA, LA) $\times 2$ (gender: boy vs. girl) repeated four measures analysis of variance (ANOVA) was conducted with movie type, trait aggressiveness, and gender as betweengroup factor, and goal word as within-group factor. According to related study [18], the score of participants at the top one third of BPAQ was defined as HA, the last one third of BPAQ was seen as LA, and the rest were thought as MA in terms of score distribution.

\subsection{Procedure}

\subsubsection{Modified STROOP Task}

Participants signed an inform consent before experiment, and then they were randomly distributed to watch violent or non-violent movie clips and filled out BPAQ, subsequently they completed STROOP task. First, instructions told that the experiment was to test speed and accuracy of responses, the goal words would be presented in different colors (green, red, and blue). If the word color was green, press " 1 " on keyboard, if the word color was blue, press " 2 ", if the word color was red, press " 3 ". Participants should react as quickly and accurately as possible to determine the word color rather than meaning, then the next trial began. After instructions began, a small sign "+" emerged on the screen centre with the time of $500 \mathrm{~ms}$, and the blank screen lasted for $100 \mathrm{~ms}$, then the words appeared on screen center for $2000 \mathrm{~ms}$. After participants reported word color, the program entered into next trial. If participants did not respond in $2000 \mathrm{~ms}$, the program also entered into next trial automatically. Meanwhile, accuracy rate and reaction time (RT) were recorded. Figure 1 showed the procedure of modified STROOP task programmed by Eprime psychology software.

\subsubsection{Experimental Sessions}

Practical session. 30 trials existed in practical session

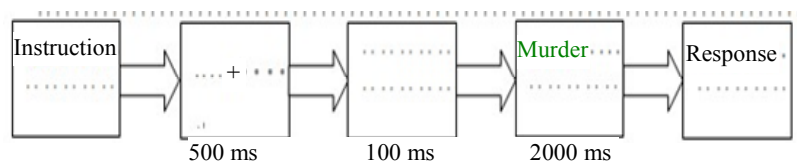

Figure 1. Modified STROOP task procedure. 
but did not appear in formal session. The program returned to practical session if the accuracy rate was below 80 percent. The session was to familiar participants with key pressing, and to exclude the color blindness. The experimenter watched beside the participants, getting ready to solve their problems.

Formal session. The formal experiment was divided into 3 blocks, in which 40 trials and totally 120 trials were presented on average. 50 aggressive and 50 nonaggressive words were presented in one of three colors, and each word appeared only once in each block. Participants had a short rest among blocks, then the program entered into the next block.

\section{RESULTS}

\subsection{The Main RT Effect of Goal Words}

One-way analysis of variance (ANOVA) was carried out to examine the main effect of goal word. The result can be seen in Table 1 .

Table 1 showed that no significant main effect of goal word was found in reaction time (RT), whereas the RT of aggressive words was significantly longer than that of nonaggressive words $(F=4.58, p<0.01)$.

\subsection{The Main Effect of Movie Type, Movie Type $\times$ Gender, Movie Type $\times$ Trait Aggressiveness Interaction}

In the present study, we hypothesized the RT of aggressive words was longer than that of nonaggressive words (compared to participants watching non-violent movie clips). Thus, we postulated each participant had an aggressively activated score (AAS), which meant the mean RT values of aggressive words subtracted nonaggressive words, representing the aggressive attitude among adolescents among each group in the study (see Table 2 ).

Table 2 showed that although the mean AAS of violent movie group $(6 \mathrm{~ms})$ was higher than that of non-violent movie group (3 ms) by watching violent movie clips, Table 3 showed no significant difference in main effect of movie type on aggression $(F=0.74, p>0.05)$.

Multi-factor analysis of variance (ANOVA) was carried out to examine whether there significant difference in AAS among independent variables. The results can be

Table 1. RT differences to aggressive and nonaggressive words.

\begin{tabular}{|c|c|c|c|c|c|}
\hline \multicolumn{6}{|c|}{ Goal words } \\
\hline & \multicolumn{2}{|c|}{ Aggressive words } & \multicolumn{2}{|c|}{ Nonaggressive words } & \multirow[t]{2}{*}{$F$} \\
\hline & $M$ & $S D$ & $M$ & $S D$ & \\
\hline RT & 540 & 52.18 & 535 & 52.07 & $4.58^{* *}$ \\
\hline
\end{tabular}

seen in Table 3.

Table 3 demonstrated that there was significant Movie Type $\times$ Gender interaction $(F=5.43, p<0.05)$. Further simple effect analysis showed the average AAS of girls watching violent and non-violent movie clips was 4.75 and 11.55, respectively, and no significant difference was found $(F=1.18, P>0.05)$. The average AAS of boys watching violent and non-violent movie clips was 7.49 and -5.44 , respectively, and that the AAS of boys watching violent movie clip was significant higher than that of boys watching non-violent movies $(F=3.84, p<$ $0.05)$. The results could be seen in Table 4.

Table 3 revealed significant Movie Type $\times$ Trait Aggressiveness interaction $(F=5.39, p<0.05)$ in AAS differences. Simple effect analysis showed the average AAS of HA adolescents watching violent and non-violent movies was 17.09 and -2.29 , respectively, and that aggression of HA adolescents was significantly affected by violent movie clips $(F=9.81, p<0.01)$. The average

Table 2. Mean AAS differences between violent movie and non-violent movie group.

\begin{tabular}{|c|c|c|c|c|c|}
\hline \multicolumn{6}{|c|}{ Goal words } \\
\hline \multirow[t]{2}{*}{ Group type } & \multicolumn{2}{|c|}{$\begin{array}{l}\text { Aggressive } \\
\text { words }\end{array}$} & \multicolumn{2}{|c|}{$\begin{array}{c}\text { Nonaggressive } \\
\text { words }\end{array}$} & \multirow[t]{2}{*}{ AAS } \\
\hline & $M$ & $S D$ & $M$ & $S D$ & \\
\hline Violent movie group & 542 & 49.07 & 536 & 48.01 & +6 \\
\hline Non-violent movie group & 537 & 55.62 & 534 & 56.73 & +3 \\
\hline Priming effect & & & & & +3 \\
\hline
\end{tabular}

Note: AAS = aggressively activated score (mean RT values of aggressive words minus nonaggressive words). Priming Effect $=$ AAS of violent movie group minus non-violent movie group.

Table 3. Multi-factor ANOVA for movie type, gender and trait agg-ressiveness in AAS.

\begin{tabular}{cccc}
\hline Independent variables & $M$ & $S D$ & $F$ \\
\hline Movie type & 237 & 23.52 & 0.74 \\
Movie type $\times$ gender & 1596 & 265.14 & $5.43^{*}$ \\
Movie type $\times$ trait aggressiveness & 1716 & 281.32 & $5.39^{*}$ \\
\hline
\end{tabular}

Note: AAS = aggressively activated score (mean RT values of aggressive words minus nonaggressive words); ${ }^{*} p<0.05 ;{ }^{* *} p<0.01 ;{ }^{* * *} p<0.001$.

Table 4. Gender differences in AAS after watching movie clips.

\begin{tabular}{cccc}
\hline Gender & Violent movie clip & Non-violent movie clip & $F$ \\
\hline Boys & 7.49 & -5.44 & $3.84^{*}$ \\
Girls & 4.75 & 11.55 & 1.18 \\
\hline
\end{tabular}

Note: AAS $=$ aggressively activated score (mean RT values of aggressive words minus nonaggressive words); ${ }^{*} p<0.05 ;{ }^{* *} p<0.01 ;{ }^{* * *} p<0.001$. 
AAS of MA adolescents watching violent and non-violent movies were 10.61 and 16.53 , respectively, and that aggression of MA participants was not significantly affected by violent movies $(F=2.82, p>0.05)$. The average AAS of LA participants watching violent and nonviolent movies was -0.66 and -2.74 , respectively, and that aggression of LA participants was not significantly affected by violent movies $(F=0.05, p>0.05)$. The results could be seen in Table 5 .

\section{DISCUSSION}

The main purpose of this study was to explore the impact of media violence on aggressive attitude of Chinese adolescents. STREET FIGHTER and AIR CRISIS were selected as media violence and media non-violence, respectively. Our study showed that no significant difference in main effect of movie type on adolescents' aggressive attitude, but demonstrated significant Movie Type $\times$ Trait Aggressiveness interaction, and that aggressive attitude of HA was significantly affected by violent movies. Further, HA adolescents showed significant higher aggressive attitude than did MA and LA adolescents. Consequently, perhaps HA adolescents were eager to choose violent movies than MA and LA adolescents, and the arising aggressive attitude of adolescents was activated by aggressively cognitive network after viewing violent movies, such that HA adolescents preferred to violent movies to non-violent movies, and aggressive attitude was easily primed by violent movies. Besides, significant Movie Type $\times$ Gender interaction was also found, and that aggressive attitude was significantly primed by violent movies only for boys, but not for girls. Specifically, boys yielded significant stronger aggressive attitude than did girls. Thus, we inferred that boys were more likely to watch violent movies than girls, thus leading to rapid development of their aggressively cognitive framework.

In consistent with our hypotheses, the study demonstrated that violent movies effectively activated the aggressive attitude of Chinese adolescents with HA, MA, and LA, which partly supporting General Aggressive

Table 5. AAS differences in trait aggressiveness after watching movie clips.

\begin{tabular}{cccc}
\hline Trait aggressiveness & Violent movie & Non-violent movie & $F$ \\
\hline HA & 17.09 & -2.29 & $9.81^{* *}$ \\
MA & 10.61 & 16.53 & 2.82 \\
LA & -0.66 & -2.74 & 0.05 \\
\hline
\end{tabular}

Note: $\mathrm{HA}=$ high trait aggressiveness; $\mathrm{MA}=$ mild trait aggressiveness; $\mathrm{LA}=$ low trait aggressiveness; AAS = aggressively activated score (mean RT values of aggressive words minus nonaggressive words); ${ }^{*} p<0.05 ;{ }^{* *} p<$ $0.01 ;{ }^{* * *} p<0.001$.
Model (GAM) [19] and Cognitive Neoassociation Model (CNM) [20], which assumed that media violence could activate individual's aggressive cognition, affect, physicological arousal, and aggressive behavior as well as traitaggressiveness formation. Additionally, we found aggressive attitude of boys was stronger than that of girls after viewing violent movies, which supported hypothesis 2, and replicated previous researches [21-25]. Moreover, aggressive attitude of HA relative to BA and LA adolescents was affected by violent movies at significant level, which was in parallel with previous studies [26-29]. It should be noticed that, however, aggressive attitude of MA and LA adolescents was not significantly affected by violent movie, which supported hypothesis 1 . Perhaps HA adolescents have stronger aggressively cognitive neoassociation networks than MA and LA adolescents, and thus their aggressive behavior was more likely to appear. Thereby, it should be confirmed that repeated exposure to violent movies formed aggressively cognitive schema for HA adolescents, and finally led them to violence and aggressive behavior. What's more, some differences existed between the present study and previous research. For instance, previous studies showed viewers' aggression was primed by violent movies, and the main effect of movie type was significant [30]. The study, rather, demonstrated no significant main effect of movie type, and that no significant difference was found in aggression between violent movie group and nonviolent movie group.

\section{CONCLUSIONS}

1) HA adolescents had a significantly stronger aggressive attitude than MA and LA adolescents after watching violent movies;

2) Boys had a significantly stronger aggressive attitude than girls after watching violent movies.

\section{ACKNOWLEDGEMENTS}

The study was supported by the National Youth Grant of National Educational Science Planning Project in 2013 (Grant Number: CBA130128), and funded by a Grant of Social Sciences and Humanities from the Ministry of Education in China (Grant Number: 13YJC190030) as well as the Fundamental Research Funds for the Central Universities (Grant Number: SWU1409135). Writing of the paper was supported by a scholarship from the China Scholarship Council (CSC) to Dr. Qian Zhang during his visit at University of Illinois at Urbana-Champaign (Grant Number: 201308505040). We thank the adolescents who participated in our study and Drs. Xiao-Fan Peng and Gang Cheng who assisted our study.

\section{REFERENCES}

[1] Wood, W., Wong, F.Y. and Chachere, J.G. (1991) Effects of media violence on viewers' aggression in uncon- 
strained social interaction. Psychological Bulletin, 109, 371-383. http://dx.doi.org/10.1037/0033-2909.109.3.371

[2] Bushman, B.J. (1997) Priming effects of media violence on the accessibility of aggressive constructs in memory. Personality and Social Psychology Bulletin, 24, 537-545. http://dx.doi.org/10.1177/0146167298245009

[3] Zeng, F.L., Dai, Q.Y., Tang, S.Q. and Zhang, W.Y. (2004) Effect of watching violent TV on aggressive behavior of adolescents. Chinese Journal of Clinical Psychology, 1, 35-37.

[4] Anderson, C.A. and Bushman, B.J. (2001) Effects of violent video games on aggressive behavior, aggressive cognition, aggressive affect, physiological arousal, and prosocial behavior: A meta-analytic review of the scientific literature. Psychological Science, 5, 353-359. http://dx.doi.org/10.1111/1467-9280.00366

[5] Huesmann, L.R., Moise-Titus, J., Podolski, C. and Eron, L.D. (2003) Longitudinal relations between children's exposure to TV violence and their aggressive and violent behavior in young adulthood: 1977-1992. Developmental Psychology, 39, 201-221. http://dx.doi.org/10.1037/0012-1649.39.2.201

[6] Carnagey, N.L. and Anderson, C.A. (2005) The effects of reward and punishment in violent video games on aggressive affect, cognition, and behavior. Psychological Science, 11, 882-889.

http://dx.doi.org/10.1111/j.1467-9280.2005.01632.x

[7] Hyde, J.S. (1984) How large are gender differences in aggression? A developmental meta-analysis. Developmental Psychology, 4, 722-736.

http://dx.doi.org/10.1037/0012-1649.20.4.722

[8] Lagerspetz, K.M., Björkqvist, K. and Peltonen, T. (1988) Is indirect aggression typical of females? Gender differences in aggressiveness in 11- to 12-year-old children. Aggressive Behavior, 14, 403-414.

http://dx.doi.org/10.1002/1098-2337(1988)14:6<403::AI D-AB2480140602>3.0.CO;2-D

[9] Crick, N.R. and Grotpeter, J.K. (1995) Relational aggression, gender, and social-psychological adjustment. Child Development, 66, 710-722. http://dx.doi.org/10.2307/1131945

[10] Lindeman, M., Harakka, T. and Keltilkangas-Jarvinen, L. (1997) Age and gender differences in adolescents' reactions to conflict situations: Aggression, pro-sociality, and withdrawal. Journal of Youth and Adolescence, 3, 339351. http://dx.doi.org/10.1007/s10964-005-0006-2

[11] Paquette, J.A. and Underwood, M.K. (1999) Gender differences in young adolescents' experiences of peer victimization: Social and physical aggression. Merrill-Palmer Quarterly, 2, 242-266.

[12] López, E.E., Pérez, S.M., Ochoa, G.M. and Ruiz, D.M. (2008) Adolescent aggression: Effects of gender and family and school environments. Journal of Adolescence, 31, 433-450.

http://dx.doi.org/10.1016/j.adolescence.2007.09.007

[13] Bushman, B.J. (1995) Moderating role of trait aggressiveness in the effects of violent media on aggression. Journal of Personality and Social Psychology, 69, 950960. http://dx.doi.org/10.1037/0022-3514.69.5.950
[14] Freedman, J.L. (2002) Media violence and its effect on aggression: Assessing the scientific evidence. Toronto: University of Toronto Press.

[15] Freedman, J.L. (1984) Effect of television violence on aggressiveness. Psychological Bulletin, 96, 227-246. http://dx.doi.org/10.1037/0033-2909.96.2.227

[16] Holden, C. (2005) Controversial study suggests seeing gun violence promotes it. Science, 308, 1239-1240. http://dx.doi.org/10.1126/science.308.5726.1239a

[17] Buss, A.H. and Perry, M.P. (1992) The aggression questionnaire. Journal of Personality and Social Psychology, 63, 452-459. http://dx.doi.org/10.1037/0022-3514.63.3.452

[18] Li, J.J., Zhang, W., Zeng, S.J., Liang, J. and Zang, C. (2008) Effect of violent computer games on individuals' aggression. Psychological Development and Education, 2, 108-112.

[19] Bushman, B.J. and Anderson, C.A. (2002) Violent video games and hostile expectations: A test of the general aggression model. Personality and Social Psychology Bulletin, 28, 1679-1689. http://dx.doi.org/10.1177/014616702237649

[20] Berkowitz, L. (1993) Aggression: Its caused, consequences, and control. New York: McGraw Hill.

[21] Salmivalli, C. and Kaukiainen, A. (2004) Female aggression revisited: Variable- and person-centered approaches to studying gender differences in different types of aggression. Aggressive Behavior, 30, 158-163. http://dx.doi.org/10.1002/ab.20012

[22] Boutwell, B.B., Franklin, C.A., Barnes, J.C. and Beaver, K.M. (2011) Physical punishment and childhood aggression: The role of gender and gene-environment interplay. Aggressive Behavior, 37, 559-568. http://dx.doi.org/10.1002/ab.20409

[23] Lansford, J.E., et al. (2012) Boys' and girls' relational and physical aggression in nine countries. Aggressive Behavior, 38, 298-308. http://dx.doi.org/10.1002/ab.21433

[24] Boutwell, B.B., Franklin, C.A., Barnes, J.C. and Beaver, K.M. (2011) Physical punishment and childhood aggression: The role of gender and gene-environment interplay. Aggressive Behavior, 37, 559-568. http://dx.doi.org/10.1002/ab.20409

[25] Bushman, B.J. and Cantor, J. (2003) Media ratings for violence and sex: Implications for policy makers and parents. American Psychologist, 58, 130-141. http://dx.doi.org/10.1037/0003-066X.58.2.130

[26] Cross, C.P. and Campbell, A. (2012) The effects of intimacy and target sex on direct aggression: Further evidence. Aggressive Behavior, 38, 272-280. http://dx.doi.org/10.1002/ab.21430

[27] Bushman, B.J. (1996) Individual difference in the extent and development of aggressive cognitive-associative networks. Personality and Social Psychology Bulletin, 22, 811-819. http://dx.doi.org/10.1177/0146167296228004

[28] Khoury, K.M. (2012) Perpetration of aggressive behaviors against peers and teachers as predicted by student and contextual factors. Aggressive Behavior, 38, 253-262. 
http://dx.doi.org/10.1002/ab.21424

[29] Wallace, M.T., Barry, C.T., Zeigler, H.V. and Green, B.A. (2012) Locus of control as a contributing factor in the relation between self-perception and adolescent aggression. Aggressive Behavior, 38, 213-221. http://dx.doi.org/10.1002/ab.21419
[30] Funk, J.B., Bechtoldt-Baldacci, H., Pasold, T. and Baumgardner, J. (2004) Violence exposure in real life, video games, television, movies, and the internet: Is there desensitization? Journal of Adolescence, 27, 23-39. http://dx.doi.org/10.1016/j.adolescence.2003.10.005 